\title{
Enteric coated mycophenolate sodium combined with low- dose steroid as first line therapy in minimal change nephrotic syndrome: an open label randomized controlled study
}

\author{
Maggie K.M. Ma ${ }^{1}$, Desmond Y.H. Yap ${ }^{1}$, Chiu Leung Li ${ }^{2}$, Maggie M.Y. Mok ${ }^{1}$, Gary C.W. \\ Chan $^{1}$, Lorraine P.Y. Kwan ${ }^{1}$, Kar Neng Lai ${ }^{1}$ and Sydney C.W. Tang ${ }^{1}$ \\ ${ }^{1}$ Division of Nephrology, Department of Medicine, The University of Hong Kong, Queen Mary Hospital, Hong Kong, China \\ ${ }^{2}$ Renal Department, Centro Hospitalar Conde de São Januário, Macao, China
}

Correspondence to: Sydney C.W. Tang, email: scwtang@hku.hk

Keywords: nephropathy; mycophenolate; minimal change disease

Received: August 21, $2017 \quad$ Accepted: December 03, 2017

Published: January 03, 2018

Copyright: $\mathrm{Ma}$ et al. This is an open-access article distributed under the terms of the Creative Commons Attribution License 3.0 (CC BY 3.0), which permits unrestricted use, distribution, and reproduction in any medium, provided the original author and source are credited.

\section{ABSTRACT}

Background: Mycophenolate has been shown to be effective in glomerular disease. However, the role of mycophenolate in the first-line treatment of adult onset idiopathic minimal change disease (MCD) has not been systematically studied in a randomized fashion.

Materials and Methods: 20 adult patients with biopsy proven MCD were recruited and randomly assigned to recevie either enteric coated Mycophenolate Sodium (ECMPS) plus low dose prednisolone (Group 1: Prednisolone $0.25 \mathrm{mg} / \mathrm{kg} / \mathrm{day}, n=10$ ) or standard dose prednisolone (Group 2: Prednisolone $1 \mathrm{mg} / \mathrm{kg} / \mathrm{day}, n=10$ ).

Results: After 24 weeks of therapy, $80 \%(n=8)$ of patients in Group 1 vs $70 \%$ $(n=7)$ of patients in Group 2 achieved complete remission $(p=0.606)$. Both groups showed a significant reduction of urine protein excretion $(p<0.05)$ and increased serum albumin $(p<0.001)$ vs baseline levels. However, no significant between-group differences were demonstrated. The relapse rate was also similar in both groups (Group 1: $10 \%$ vs Group 2: 10\%). EC-MPS treatment was well tolerated but 5 out of 10 patients from the standard-dose prednisolone group reported adverse reaction towards the assigned treatment.

Conclusions: EC-MPS plus low dose prednisolone is non-inferior to standarddose prednisolone therapy in inducing clinical remission and preventing relapse in adult onset idiopathic MCD and is associated with better tolerability and less adverse effects. This trial is registered with the ClinicalTrials.gov number NCT01185197.

\section{INTRODUCTION}

Idiopathic minimal change disease (MCD) is the second commonest cause of primary nephrotic syndrome in adults [1]. Although conventional treatment with highdose oral corticosteroid induces clinical remission in the majority of subjects [2], considerable cushingnoid side effects are inevitable which may be a significant source of distress and non-compliance particularly in young adults. Mycophenolic acid (MPA)-based therapy was first shown to be effective in isolated cases of primary glomerular disease in 2002 [3]. Subsequently it was also reported in randomized studies to induce remission of proteinuria in
IgA nephropathy $[4,5]$, and achieve equivalent therapeutic efficacy when compared with standard Ponticelli regimen in idiopathic membranous nephropathy [6]. More recently, mycophenolate is reported to be a less toxic adjuvant agent for remission maintenance in childhood-onset relapsing or steroid-dependent MCD compared with cyclosporine [7-9]. In adults, mycophenolate is also shown to be a promising alternative treatment in a case series of 5 subjects [10]. In hepatitis B carriers, mycophenolate combined with half standard-dose prednisolone therapy has been shown to induce remission with reduced rates of HBV reactivation [11]. However, the role of mycophenolate in the primary treatment of adult onset 
MCD has not been systematically studied in a randomized fashion.

We therefore performed a prospective, open-label, randomized study to investigate the potential therapeutic efficacy of enteric-coated mycophenolate sodium (ECMPS) combined with low-dose corticosteroid as firstline treatment for idiopathic minimal change disease in adult patients who presented for the first time with biopsy proven MCD. This study aimed to determine whether mycophenolate is as effective a form of treatment for idiopathic MCD as standard therapy, but with a more favourable side-effect profile and patient tolerability.

\section{RESULTS}

\section{Participants}

20 patients (10 in Group 1 and Group 2 respectively) were recruited into the study (Figure 1). 1 patient who was assigned to Group 1 was lost to follow-up after week 8 . There were 2 more patients who defaulted the extended follow-up peroid in Group 1 after completion of the 24week assigned treatment. The demographic characteristics and baseline clinical and laboratory data were summarized in Table 1. The doses of ACE inhibitors/ARBS and statins of the 20 patients at baseline and 48 months were presented in Supplementary Table 1. There were no significant differences in the 24-hour urine protein and serum albumin levels between the 2 groups. Group 1 patients were younger (mean age in Group $131.9 \pm 13.5$ years $v s$ Group $256.9 \pm 19.3$ years, $p=0.002$ ) and had higher eGFR (Group $1118.2 \pm 30.3$ vs Group $72.3 \pm 30.3$ $\mathrm{ml} / \mathrm{min} / 1.73 \mathrm{~m}^{2}, p=0.003$ ) than group 2 patients.

\section{Response to therapy}

One patient from Group 1 was lost to follow-up at week 8 and was counted as treatment failure. After 24 weeks of therapy, $80 \%(8 / 10)$ of patients in Group 1 and $70 \%(7 / 10)$ of patients in Group 2 achieved complete remission $(p=0.606)$. Figure 2 showed the Kaplan Meier curve of complete remission rate of the 2 groups over the 24-week study period ( $P=0.59, \log$-rank test).

One patient from Group 1 failed to achieve complete remission by week 12 and was switched to standard therapy. Three other patients from Group 2 achieved partial remission after 24 weeks of treatment.

\section{Clinical and laboratory parameters}

There was significant reduction of urine protein excretion in both Group 1 and Group 2 after the 24-week treatment ( $p$ value for time trend for group 1 and group 2 both $<0.05)$. However, the overall change of urine protein excretion between the 2 groups did not differ significantly (Figure 3A). Similarly, there was a significant increase in serum albumin ( $p$ value for time trend for group 1 and group 2 both $<0.001$ ) but without significant betweengroup difference (Figure 3B).

Other clinical and laboratory parameters of the 2 groups over the 24-week study period were summarized in Table 2.

\section{Relapse}

Two out of 10 patients (20\%) from Group 1 developed relapse of nephrotic syndrome over the 48week follow-up. One of them occurred at week 24 due to treatment non-compliance. The patient was given standard prednisolone therapy and achieved complete remission thereafter. The other occurred at week 32 and was preceded by upper respiratory infection. Two patients (20\%) from Group 2 relapsed. One patient developed relapse at week 16 while the dose of prednisolone was being tapered. The patient achieved complete remission at week 8 but developed relapse after a flu-like illness. Another patient developed relapse at week 33 (Figure 4, $\log$ rank test $p=0.78$ ).

\section{Adverse effects}

Patients from both groups did not have cytopenia or steroid induced diabetes in the 24-week treatment period. Group 1 patients mostly tolerated treatment well except one patient developed cellulitis over her edematous lower limb and another patient complained of acne during the early course of treatment. Five Group 2 patients complained of adverse effects including moon face $(n=3)$, mild joint pain $(n=1)$, facial erythema $(n=1)$, epigastric pain $(n=1)$ and insomnia $(n=1)$. One Group 1 patient complained of abdominal striae and one Group 2 patients developed herpes zoster after receiving high dose steroid for relapse of nephrotic syndrome during the extended 24week follow-up period.

There was 1 patient from Group 1 who defaulted. During the 8-week follow-up, her urine protein excretion decreased from $10.7 \mathrm{~g} / 24$ hours at week 0 to $2.95 \mathrm{~g} / 24$ hours at week 8 . She did not report any adverse reaction to the treatment. Kidney function and blood count remained stable.

\section{DISCUSSION}

Mycophenolate blocks purine biosynthesis, inhibits $\mathrm{T}$ and B-lymphocyte proliferation [13]. In recent years, MPA-based therapy has been introduced in the treatment of primary glomerulopathies [9]. Mycophenolate mofetil (MMF) and enteric coated Mycophenolate Sodium are the two prodrugs of MPA. To date, most of the evidences of MPA-based therapy in nephrotic syndrome were derived from the paediatric population using MMF. It had been shown that MMF is safe and efficacious in the treatment 
of steroid dependent nephrotic syndrome in children and can be used as a steroid sparing agent [14]. Compared with calcineurin inhibitors such as cyclosporine A, MMF has a better side effect profile. Patients on MMF had better eGFR than those on cyclosporine A [7]. Hence, MMF would be a good alternative immunosuppressant, particularly in patients who had evidence of calcineurin inhibitor toxicity [15]. In adults, a case series reported successful discontinuation of steroid treatment in 4 out of 5 cases of steroid dependent or frequently relapsing MCD after using ES-MPS [10]. In hepatitis B carriers, MMF combined with half standard-dose prednisolone therapy has been shown to induce remission with reduced rates of HBV reactivation [11]. Nevertheless, high quality evidence on the use of mycophenolate in MCD remains lacking. Currently, the KDIGO guideline only recommends using $\mathrm{MMF}$ for adult MCD patients who are intolerant to corticosteroids, cyclophosphamide and calcineurin inhibitors [12].

To our knowledge, this is the first open-label randomized controlled study investigating the treatment efficacy of enteric coated Mycophenolate Sodium plus low dose prednisolone as primary treatment of adult onset idiopathic minimal change disease. We demonstrated a comparable complete remission rate between the Mycophenolate group (80\%) and standard-dose steroid group (70\%). Both groups also had very low relapse rates $(20 \%)$ up to the 48 -week follow-up time point. These relapses were mostly due to drug non-compliance or precipitation by flu-like illness. It is worth noting that there

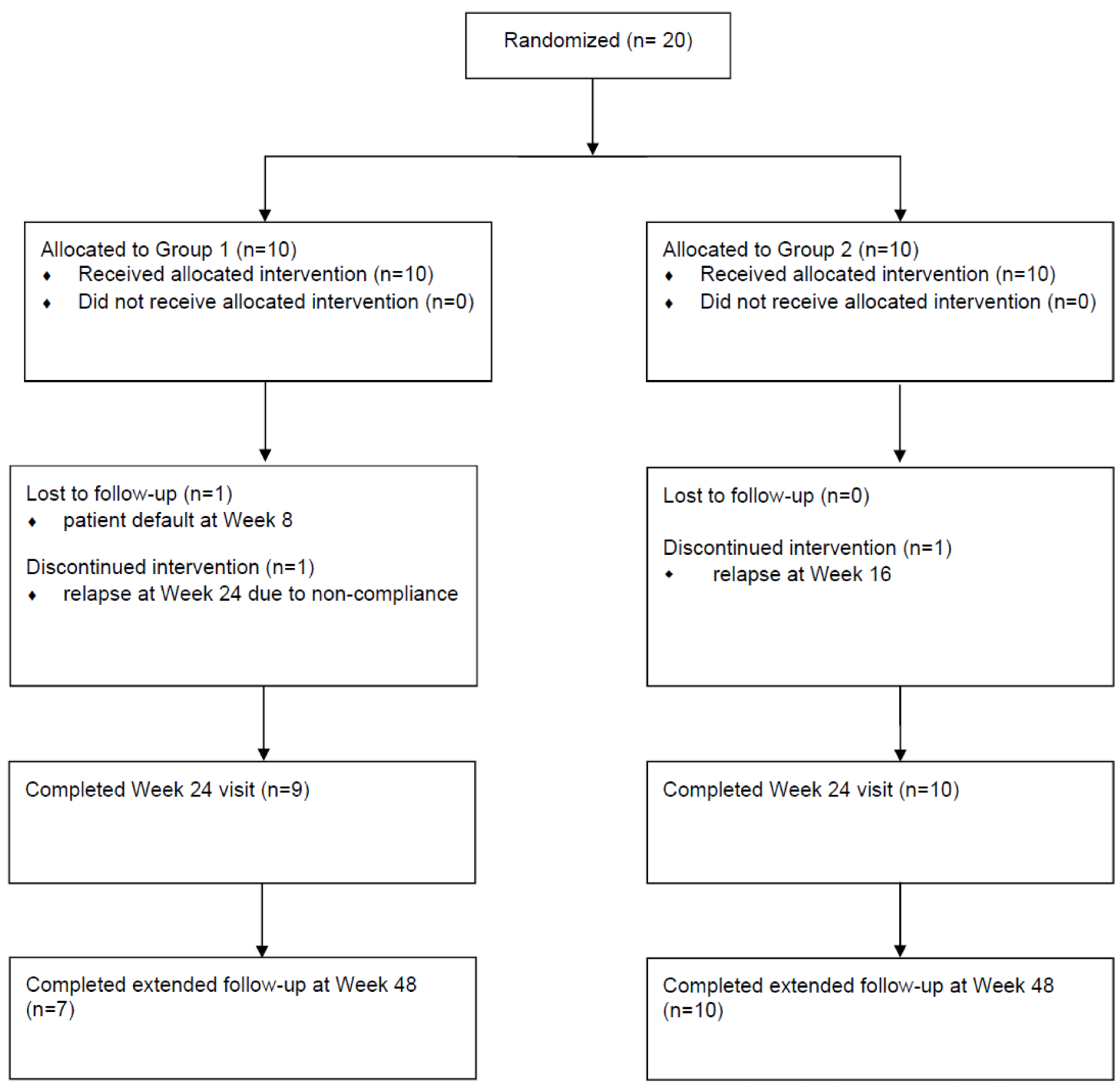

Figure 1: Patient randomization flow diagram. 
Table 1: Baseline characteristics of patients with treatment naïve idiopathic MCD

\begin{tabular}{lccc}
\hline & $\begin{array}{c}\text { Group 1 }(\boldsymbol{n}=\mathbf{1 0}) \\
\text { mycophenolate plus low-dose } \\
\text { steroid }\end{array}$ & $\begin{array}{c}\text { Group 2 }(\boldsymbol{n}=\mathbf{1 0}) \\
\text { standard-dose } \\
\text { steroid }\end{array}$ & P value \\
\hline Demographic data & & & \\
Age (y) & $31.9 \pm 13.5$ & $56.9 \pm 19.3$ & 0.002 \\
Male Gender & $5(50 \%)$ & $3(50 \%)$ & 0.99 \\
Clinical parameters at week 0 & & & 0.47 \\
Body weight $(\mathrm{kg})$ & $65.3 \pm 19.4$ & $60.4 \pm 7.4$ & 0.24 \\
BMI (kg/m2) & $29.2 \pm 13.5$ & $23.1 \pm 5.7$ & 0.18 \\
Systolic BP (mmHg) & $129.9 \pm 17.4$ & $140.9 \pm 17.7$ & 0.81 \\
Diastolic BP (mmHg) & $77.9 \pm 15.8$ & $79.4 \pm 10.9$ & 0.06 \\
Laboratory parameters at week 0 & & $102.4 \pm 50.1$ & 0.003 \\
Creatinine $(\mu \mathrm{mol} / \mathrm{l})$ & $69.4 \pm 15.6$ & $72.3 \pm 30.3$ & 0.96 \\
eGFR (ml/min/1.73m2) & $118.2 \pm 30.3$ & $6.1 \pm 3.1$ & 0.88 \\
24 hours urine protein $(\mathrm{g})$ & $6.1 \pm 2.9$ & $20.9 \pm 4.3$ & \\
Serum albumin $(\mathrm{g} / \mathrm{l})$ & $18.6 \pm 5.6$ & & \\
\hline
\end{tabular}

were also less adverse reactions in patients who received mycophenolate and most of these adverse reactions were likely steroid related complications.
Limitations of this study include its small sample size and open-label design. Patients from the standarddose prednisolone group were older, more hypertensive

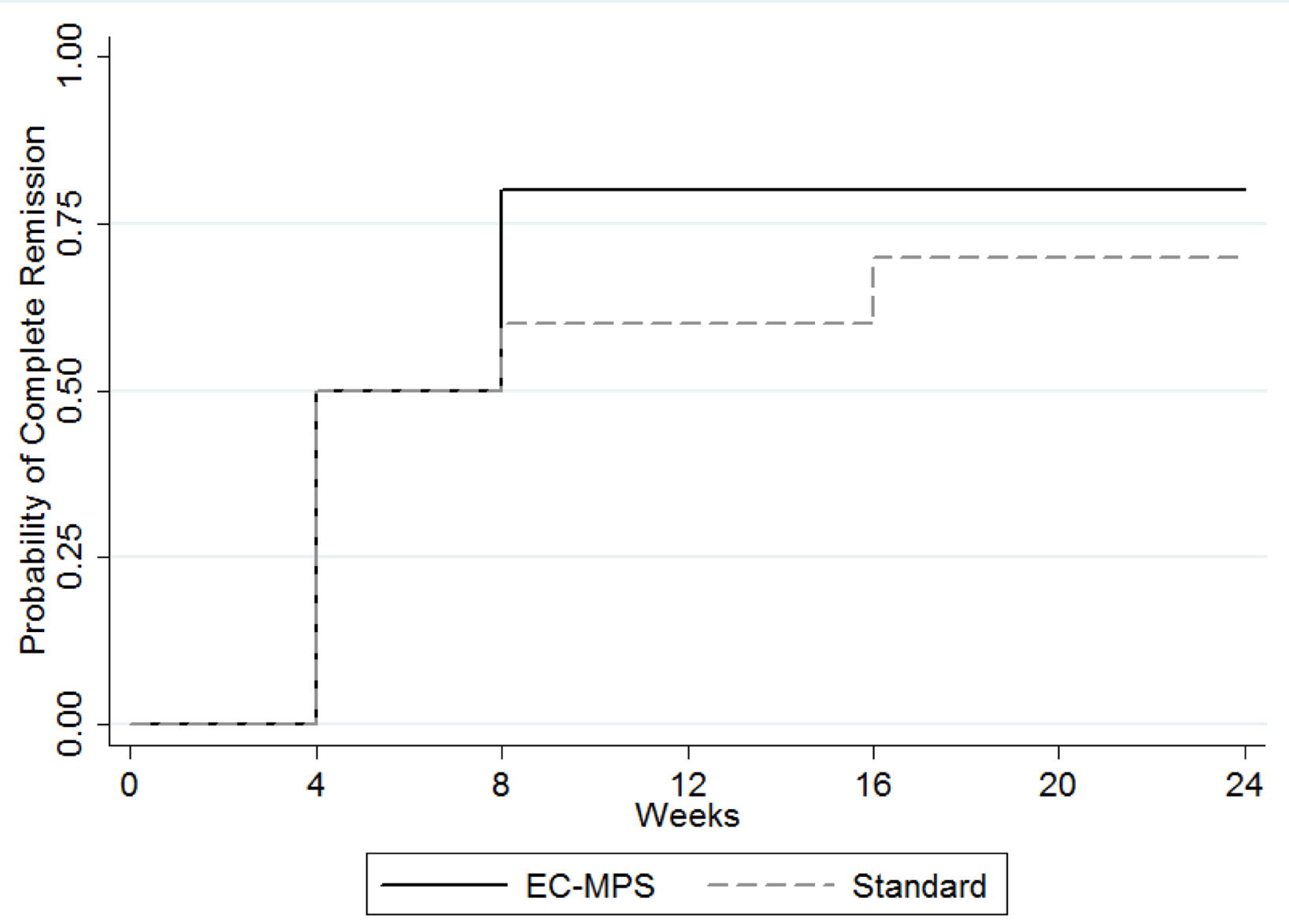

Figure 2: Kaplan-Meier analysis of the probability of complete remission during the 24 weeks of treatment $(P=0.59$, log-rank test). 
and had worse kidney function at baseline than those received ES-MPS. They represented the high risk group who may response poorly to treatment. Yet, these patients demonstrated significant improvement in systolic and diastolic BPs and trend of improving serum creatinine over time, suggesting steroid therapy had good effects from these parameters. On the other hand, as there were less hypertensive patients and patients with abnormal kidney function in the ES-MPS group, the efficacy of ES-MPS for these higher risk patients had to be verified in other larger randomized controlled trial. Overall, patients from both groups responded well to their assigned treatment and their complete remission rates were comparable to those published in the literature. There was one patient who defaulted follow-up in the mycophenolate group. She did show partial response after 8 weeks of mycophenolate treatment and did not have major side effects.

In conclusion, this preliminary, small, open-label trial showed that enteric coated Mycophenolate Sodium plus low dose prednisolone achieved similar efficacy to standard-dose prednisolone therapy in treatment of minimal disease with nephrotic syndrome. This therapeutic approach was also associated with better tolerability and less adverse effects. Future large randomized, double-blind trials to verify the potential therapeutic role of enteric coated Mycophenolate Sodium as first-line treatment of adult onset idiopathic of MCD is warranted.

\section{MATERIALS AND METHODS}

\section{Participants and study design}

This was a 24-week open-label, randomised controlled study. Male or female aged 18 years or above

A



Week 0 Week 4 Week 8 Week 16 Week 24 with first histological diagnosis of treatment-naïve $\mathrm{MCN}$ who were willing to give written, informed consent had been included. Those patients who had secondary causes of MCD (such as connective tissue disease or malignancy); prior history of glomerular disease including MCD; concomitant renal pathologies in addition to MCD on renal biopsy; known allergy to mycophenolate; concurrent treatment with corticosteroids; non-steroidal anti-inflammatory drugs or immunosuppressive agent; female who are pregnant or intending to conceive; female of child-bearing age who are unwilling to practice effective contraception or patient who are unable to give informed consent have been excluded.

Consenting and eligible subjects had been randomized in a 1:1 ratio to either of the following treatment groups:

Group 1 (EC-MPS plus low-dose steroid): Prednisolone $0.25 \mathrm{mg} / \mathrm{kg} /$ day for 8 weeks then $0.15 \mathrm{mg}$ / $\mathrm{kg} /$ day for 8 weeks then $0.1 \mathrm{mg} / \mathrm{kg} /$ day for 8 weeks then off, plus EC-MPS $720 \mathrm{mg}$ b.i.d. (540 mg b.i.d. if body weight less than $60 \mathrm{~kg}$ ) for 24 weeks then off

Group 2 (Standard-dose steroid): Prednisolone 1 $\mathrm{mg} / \mathrm{kg} /$ day to be tapered over a period of 24 weeks at the discretion of the attending physician

All patients were also given treatment including angiotensin converting enzyme inhibitor/ Angiotensin receptor blocker with or without other anti-hypertensive and statin. The choice of other anti-hypertensive agents to achieve target blood pressure $(<130 / 80 \mathrm{mmHg})$ includes calcium channel blocker, beta-blocker, thiazide, and alphablocker. Study visits occurred at D0 (Randomization), week $2,4,8,16,24,36,48$. After cessation of immunosuppressive treatment at week 24 , patients had an extended period of follow-up till week 48 to monitor for clinical relapse.

B

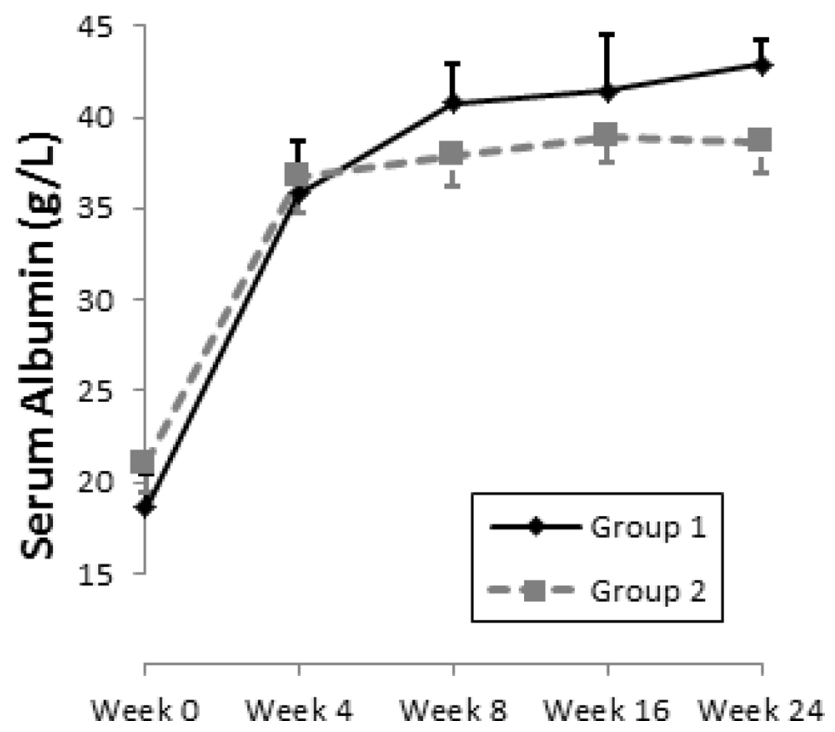

Figure 3: Change of urine protein excretion and serum albumin throughout the 24-week follow-up. Data presented are the mean values and the standard errors 
This study was conducted in accordance with the guidelines set out in the Declaration of Helsinki and ICH-Good Clinical Practice. The study protocol was approved by the Institutional Review Board (IRB reference number: HKU/HA HKW IRB UW 10-190). This trial was also registered with the ClinicalTrials.gov number NCT01185197.

\section{Outcome}

The primary endpoint was complete remission rate, which was defined as 24-hour urine protein $<0.3$ $\mathrm{g}$ at 6 months. The secondary endpoints were partial remission rate (defined as proteinuria $>0.3$ but $<3.5$ $\mathrm{g} / 24$ hours); relapse rate within 6 months of treatment cessation (defined as presence of proteinuria using urine dipsticks on 3 non-consecutive days); change in 24-hour urine protein excretion, serum albumin, serum creatinine, eGFR, serum lipid profile, haemoglobin, white blood cell count, blood pressure and body weight. Untoward effects including gastrointestinal upset, cytopenia, infection, and other steroid-related complications and patient-perceived aesthetic effects (presence of moon face, acnes, striae, weight gain) were also recorded. Patients randomized to
Group I who failed to achieve complete remission after 12 weeks of therapy were considered to have treatment failure and were switched to conventional therapy.

\section{Statistical considerations}

We had previously reported $94 \%$ and $100 \%$ complete remission rate in younger and older MCD patients after completing 16-week of corticosteroid therapy respectively [16]. Our study was designed to show that EC-MPS treatment was non-inferior to standard steroid therapy with a noninferiority margin of 0.3 in terms of response rate. Assuming the response rate of steroid treatment was $90 \%$, recruitment of 10 patients in each arm would achieve $70 \%$ of power at a significance level of 0.05 . We used an intention-to-treat approach to perform analyses in patients who had received at least one dose of a study drug. Comparisons between groups were performed by chi-squared statistic for categorical data, and Mann-Whitney U as appropriate for continuous data. Complete remission rate and relapse-free survival were calculated using the Kaplan-Meier method, and analyzed using log-rank statistics. The longitudinal measurements of clinical and laboratory parameters were analysed using repeated measure ANOVA to determine time trend and between group

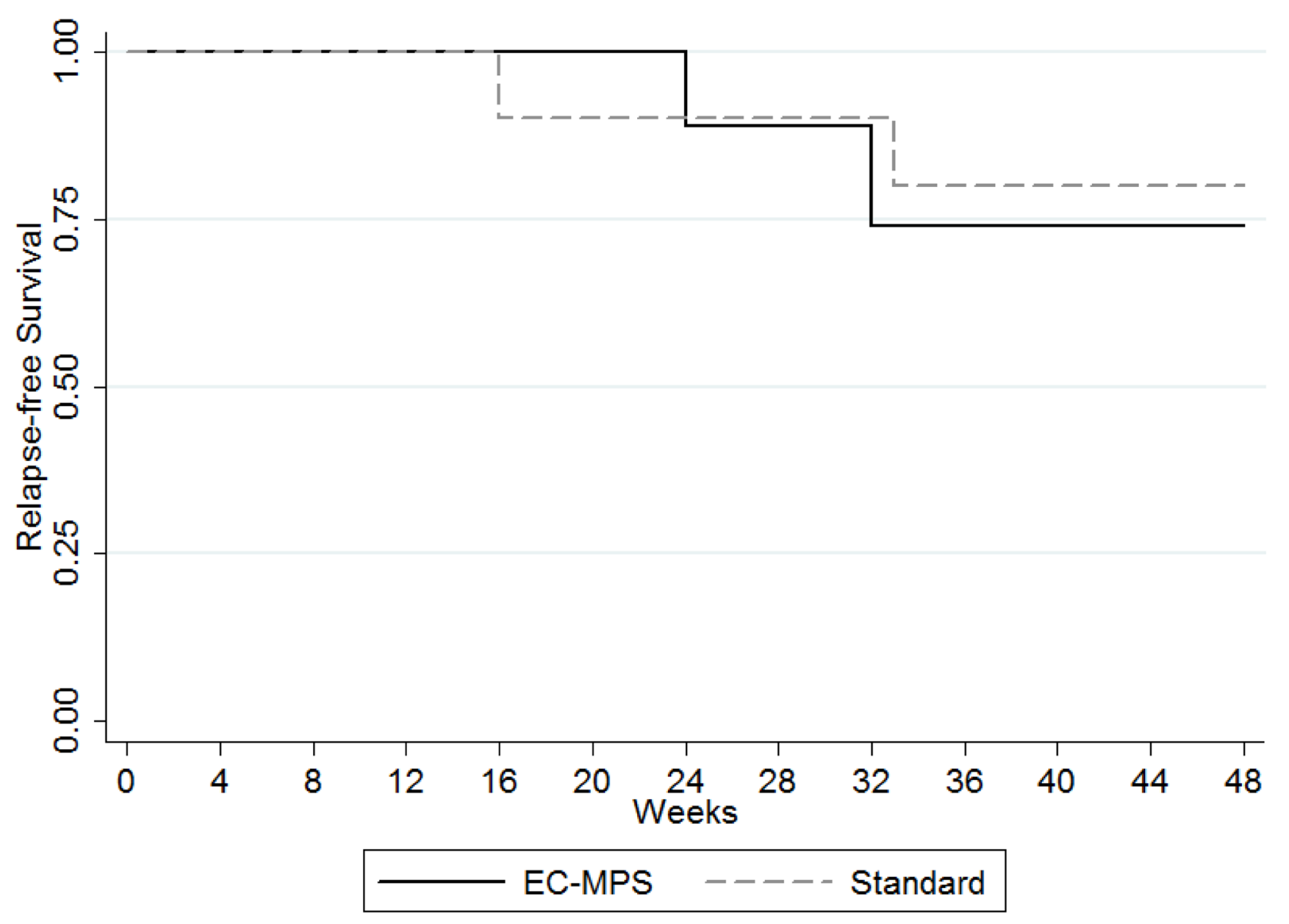

Figure 4: Kaplan-Meier analysis of relapse free survival of the 20 study patients $(P=0.78, \log -r a n k$ test $)$. 
Table 2: Clinical and laboratory parameters throughout the 24-week follow-up

\begin{tabular}{|c|c|c|c|c|c|c|c|c|}
\hline & $\begin{array}{c}\text { Treatment } \\
\text { group }\end{array}$ & Week 0 & Week 2 & Week 4 & Week 8 & Week 16 & Week 24 & $\begin{array}{l}P \text { value for } \\
\text { time trend }\end{array}$ \\
\hline \multirow[t]{2}{*}{ Systolic BP (mmHg) } & Group 1 & $129 \pm 13$ & $122 \pm 12$ & $123 \pm 7$ & $120 \pm 13$ & $122 \pm 14$ & $128 \pm 19$ & 0.25 \\
\hline & Group 2 & $141 \pm 18$ & $125 \pm 18$ & $128 \pm 14$ & $117 \pm 18$ & $121 \pm 19$ & $116 \pm 16$ & 0.04 \\
\hline \multirow[t]{2}{*}{ Diastolic BP (mmHg) } & Group 1 & $75 \pm 12$ & $74 \pm 11$ & $74 \pm 9$ & $73 \pm 9$ & $72 \pm 9$ & $72 \pm 14$ & 0.81 \\
\hline & Group 2 & $79 \pm 11$ & $75 \pm 11$ & $73 \pm 10$ & $66 \pm 9$ & $71 \pm 12$ & $71 \pm 11$ & 0.02 \\
\hline \multirow[t]{2}{*}{ Body weight (kg) } & Group 1 & $65.7 \pm 20.5$ & $63.9 \pm 22.0$ & $62.6 \pm 17.9$ & $62.3 \pm 18.0$ & $63.8 \pm 19.1$ & $64.1 \pm 20.3$ & 0.25 \\
\hline & Group 2 & $60.5 \pm 7.9$ & $57.4 \pm 5.5$ & $57.0 \pm 5.9$ & $56.8 \pm 6.3$ & $57.8 \pm 6.1$ & $58.1 \pm 6.8$ & 0.04 \\
\hline \multirow[t]{2}{*}{${ }^{\Delta} \mathrm{BW}$ from baseline $(\mathrm{kg})$} & Group 1 & 0 & $-1.9 \pm 4.5$ & $-3.1 \pm 3.9$ & $-3.5 \pm 4.3$ & $-1.9 \pm 3.4$ & $-1.6 \pm 2.6$ & 0.25 \\
\hline & Group 2 & 0 & $-3.1 \pm 3.4$ & $-3.5 \pm 3.9$ & $-3.7 \pm 4.6$ & $-2.7 \pm 4.0$ & $-2.4 \pm 4.2$ & 0.04 \\
\hline \multirow[t]{2}{*}{ Neck circumference $(\mathrm{cm})$} & Group 1 & $34.9 \pm 4.5$ & & & & & $34.3 \pm 4.6$ & 0.12 \\
\hline & Group 2 & $34.1 \pm 3.1$ & & & & & $33.7 \pm 2.6$ & 0.55 \\
\hline \multirow[t]{2}{*}{ Hip Wrist ratio } & Group 1 & $1.19 \pm 0.13$ & & & & & $1.20 \pm 0.13$ & 0.44 \\
\hline & Group 2 & $1.12 \pm 0.11$ & & & & & $1.14 \pm 0.13$ & 0.43 \\
\hline \multirow[t]{2}{*}{ Calf circumference $(\mathrm{cm})$} & Group 1 & $36.5 \pm 4.5$ & $35.7 \pm 5.2$ & $35.4 \pm 3.9$ & $35.5 \pm 3.7$ & $35.5 \pm 3.8$ & $36.4 \pm 4.6$ & 0.46 \\
\hline & Group 2 & $35.0 \pm 3.2$ & $34.6 \pm 3.0$ & $33.9 \pm 2.4$ & $32.4 \pm 6.8$ & $34.5 \pm 3.0$ & $34.5 \pm 3.3$ & 0.27 \\
\hline \multirow[t]{2}{*}{ Creatinine $(\mu \mathrm{mol} / \mathrm{L})$} & Group 1 & $69 \pm 16$ & $75 \pm 16$ & $71 \pm 14$ & $70 \pm 14$ & $69 \pm 18$ & $71 \pm 15$ & 0.78 \\
\hline & Group 2 & $102 \pm 50$ & $90 \pm 19$ & $85 \pm 13$ & $82 \pm 15$ & $82 \pm 19$ & $81 \pm 17$ & 0.12 \\
\hline \multirow[t]{2}{*}{$\mathrm{eGFR}^{*}$} & Group 1 & $118 \pm 30$ & $108 \pm 35$ & $114 \pm 28$ & $113 \pm 22$ & $126 \pm 49$ & $113 \pm 25$ & 0.51 \\
\hline & Group 2 & $72 \pm 30$ & $76 \pm 16$ & $77 \pm 10$ & $82 \pm 6$ & $82 \pm 13$ & $83 \pm 13$ & 0.34 \\
\hline \multirow[t]{2}{*}{ Leucocyte count $\left(\mathrm{x} 10^{9} / \mathrm{L}\right)$} & Group 1 & $6.5 \pm 2.0$ & $10.1 \pm 3.5$ & $8.7 \pm 3.2$ & $8.8 \pm 2.8$ & $8.1 \pm 3.3$ & $7.2 \pm 2.0$ & 0.02 \\
\hline & Group 2 & $7.1 \pm 3.4$ & $14.2 \pm 4.4$ & $12.0 \pm 3.9$ & $11.7 \pm 2.9$ & $10.1 \pm 2.9$ & $8.8 \pm 2.7$ & $<0.001$ \\
\hline \multirow[t]{2}{*}{ Lymphocyte count $\left(\mathrm{x} 10^{9} / \mathrm{L}\right)$} & Group 1 & $1.94 \pm 0.6$ & $2.3 \pm 1.1$ & $2.1 \pm 0.9$ & $2.8 \pm 1.1$ & $1.8 \pm 0.7$ & $2.2 \pm 0.5$ & 0.14 \\
\hline & Group 2 & $1.6 \pm 0.4$ & $1.9 \pm 1.5$ & $2.3 \pm 1.5$ & $2.8 \pm 1.1$ & $2.6 \pm 1.6$ & $2.9 \pm 1.1$ & 0.05 \\
\hline \multirow[t]{2}{*}{ Fasting glucose $(\mathrm{mmol} / \mathrm{L})$} & Group 1 & $5.1 \pm 0.5$ & & & $4.8 \pm 0.5$ & & $4.8 \pm 0.5$ & 0.14 \\
\hline & Group 2 & $5.8 \pm 0.9$ & & & $5.4 \pm 1.0$ & & $4.8 \pm 0.5$ & 0.02 \\
\hline \multirow[t]{2}{*}{ Total cholesterol (mmol/L) } & Group 1 & $11.3 \pm 4.0$ & & & $5.3 \pm 0.7$ & & $5.5 \pm 2.4$ & 0.01 \\
\hline & Group 2 & $8.8 \pm 3.2$ & & & $5.9 \pm 1.0$ & & $4.7 \pm 1.1$ & 0.01 \\
\hline
\end{tabular}

"Between group $P$ value $<0.05$

differences. Statistical analyses were performed using SPSS version 16.0 (SPSS Inc., Chicago, IL, USA), with $p$-values of $<0.05$ considered statistically significant.

\section{Author contributions}

Conception or design, or analysis and interpretation of data, or both: Maggie K.M. Ma and Sydney C.W. Tang Patient recruitment and follow up: Maggie K.M. Ma, Desmond Y.H. Yap, Chiu Leung Li, Maggie M.Y. Mok, Gary C.W. Chan, Lorraine P.Y. Kwan, Kam Wa Chan and Sydney C.W. Tang. Drafting the article or revising it: Maggie K.M. Ma, Sydney C.W. Tang. Providing intellectual content of critical importance to the work described: Maggie K.M. Ma, Sydney C.W. Tang. Final approval of the version to be published: Kar Neng Lai, Sydney C.W. Tang.

\section{ACKNOWLEDGMENTS}

The authors thank Ms Sandra Luen for providing clerical support.

\section{CONFLICTS OF INTEREST}

None.

\section{FUNDING}

This study was supported by Mr Winston Leung, Mrs. Rita T. Liu SBS of L \& T Charitable Foundation Ltd \& Indo Café, Mr. K.K. Chan of the Hong Kong Concrete Co. Ltd and an Endowment Fund established for the 'Yu Professorship in Nephrology' at the University of Hong Kong awarded to S.C.W.T.

\section{REFERENCES}

1. Orth SR, Ritz E. The nephrotic syndrome. N Engl J Med. 1998; 338:1202-11. https://doi.org/10.1056/ NEJM199804233381707.

2. Tang SC, Lai KN. Some Specific Glomerulonephritides. In: Chan TM and M.K. C, eds. Integrated Systematic 
Nephrology. (Hong Kong: Hong Kong University Press). 2005; pp. 71-80.

3. Choi MJ, Eustace JA, Gimenez LF, Atta MG, Scheel PJ, Sothinathan R, Briggs WA. Mycophenolate mofetil treatment for primary glomerular diseases. Kidney Int. 2002; 61:1098-114. https://doi.org/10.1046/j.15231755.2002.00214.x.

4. Tang S, Leung JC, Chan LY, Lui YH, Tang CS, Kan CH, Ho YW, Lai KN. Mycophenolate mofetil alleviates persistent proteinuria in IgA nephropathy. Kidney Int. 2005; 68:80212. https://doi.org/10.1111/j.1523-1755.2005.00460.x.

5. Tang SC, Tang AW, Wong SS, Leung JC, Ho YW, Lai KN. Long-term study of mycophenolate mofetil treatment in IgA nephropathy. Kidney Int. 2010; 77:543-9. https://doi. org/10.1038/ki.2009.499.

6. Chan TM, Lin AW, Tang SC, Qian JQ, Lam MF, Ho YW, Tse KC, Chan KW, Lai KN, Tang CS. Prospective controlled study on mycophenolate mofetil and prednisolone in the treatment of membranous nephropathy with nephrotic syndrome. Nephrology (Carlton). 2007; 12:576-81. https:// doi.org/10.1111/j.1440-1797.2007.00822.x.

7. Dorresteijn EM, Kist-van Holthe JE, Levtchenko EN, Nauta J, Hop WC, van der Heijden AJ. Mycophenolate mofetil versus cyclosporine for remission maintenance in nephrotic syndrome. Pediatr Nephrol. 2008; 23:2013-20. https://doi. org/10.1007/s00467-008-0899-6.

8. Fujinaga S, Ohtomo Y, Hirano D, Nishizaki N, Someya T, Ohtsuka Y, Kaneko K, Shimizu T. Mycophenolate mofetil therapy for childhood-onset steroid dependent nephrotic syndrome after long-term cyclosporine: extended experience in a single center. Clin Nephrol. 2009; 72:268-73.

9. Sepe V, Libetta C, Giuliano MG, Adamo G, Dal Canton A. Mycophenolate mofetil in primary glomerulopathies.
Kidney Int. 2008; 73:154-62. https://doi.org/10.1038/ sj.ki.5002653.

10. Siu YP, Tong MK, Leung K, Kwan TH, Au TC. The use of enteric-coated mycophenolate sodium in the treatment of relapsing and steroid-dependent minimal change disease. $\mathrm{J}$ Nephrol. 2008; 21:127-31.

11. Li X, Tian J, Wu J, He Q, Li H, Han F, Li Q, Chen Y, Ni $\mathrm{Q}$, Chen J. A comparison of a standard-dose prednisone regimen and mycophenolate mofetil combined with a lower prednisone dose in Chinese adults with idiopathic nephrotic syndrome who were carriers of hepatitis B surface antigen: a prospective cohort study. Clin Ther. 2009; 31:741-50. https://doi.org/10.1016/j.clinthera.2009.04.011.

12. Chapter 5: Minimal-change disease in adults. Kidney Int. 2012; 2:177-80. https://doi.org/10.1038/kisup.2012.18.

13. Allison AC, Eugui EM. Mycophenolate mofetil and its mechanisms of action. Immunopharmacology. 2000; 47:85118.

14. Afzal K, Bagga A, Menon S, Hari P, Jordan SC. Treatment with mycophenolate mofetil and prednisolone for steroiddependent nephrotic syndrome. Pediatr Nephrol. 2007; 22:2059-65. https://doi.org/10.1007/s00467-007-0617-9.

15. Barletta GM, Smoyer WE, Bunchman TE, Flynn JT, Kershaw DB. Use of mycophenolate mofetil in steroiddependent and -resistant nephrotic syndrome. Pediatr Nephrol. 2003; 18:833-7. https://doi.org/10.1007/s00467003-1175-4.

16. Tse KC, Lam MF, Yip PS, Li FK, Choy BY, Lai KN, Chan TM. Idiopathic minimal change nephrotic syndrome in older adults: steroid responsiveness and pattern of relapses. Nephrol Dial Transplant. 2003; 18:1316-20. 